\title{
Path Analysis of Attitude Toward Health Checkup and Breast Cancer on the Application of Physical Therapy after Breast Cancer Surgery
}

\author{
Mi-Joung Lee, PT, PhD $\cdot$ Hyo-Lyun Ro, PT, $\mathrm{PhD}^{1 \dagger}$ \\ Discipline of Physiotherapy, The University of Sydney \\ ${ }^{1}$ Department of Physical Therapy, Kangwon National University
}

Received: September 20, 2021 / Revised: September 24, 2021 / Accepted: October 26, 2021

(C) 2021 J Korean Soc Phys Med

\begin{abstract}
| Abstract |
PURPOSE: This study examined women's attitudes toward the use of physical therapy in the treatment process after breast cancer surgery and the degree of interest in this application. Path analysis was conducted to discover the approaches to improve awareness of the necessity of physical therapy intervention after breast cancer surgery.
\end{abstract}

METHODS: This study was a cross-sectional survey of 230 women aged 20 years and over with no history of breast cancer. The measurement tool used in this study was a structured questionnaire, composed of 17 items in five fields: five items on the demographic characteristics, four items related to health checkups, four items involving the viewpoints on breast cancer, one item related to the interest in breast cancer, and four items related to physical therapy after surgery.

RESULTS: Women's attitudes toward regular health

$\dagger$ Corresponding Author : Hyo-Lyun Ro

withtry@kangwon.ac.kr, https://orcid.org/0000-0002-0187-7109

This is an Open Access article distributed under the terms of the Creative Commons Attribution Non-Commercial License (http://creativecommons.org/licenses/by-nc/3.0) which permits unrestricted non-commercial use, distribution, and reproduction in any medium, provided the original work is properly cited. checkups were major factors in the prevention and treatment of breast cancer. In addition, those with higher levels of interest in breast cancer showed stronger interest in using physical therapy after breast cancer surgery.

CONCLUSION: Women believe that breast cancer can be prevented through the health checkups implemented by the government. Therefore, there is a need to utilize public relations to promote methods for the self-diagnosis of breast cancer in the health checkup system and the use of physical therapy after breast cancer surgery.

Key Words: Breast cancer, Health checkup, Physical Therapy

\section{Introduction}

Breast cancer is a mass (a palpable mass) comprised of cancer cells in the breast. In general, breast cancer refers to cancer that arises from the ducts and lobules of the breast. Breast cancer should include the following elements: breast mass, breast pain, nipple discharge, nipple or skin retraction, axillary mass or pain, arm swelling, symptoms of possible metastatic spread, and suspicious findings on routine mammography. More than 1.2 million women are diagnosed with breast cancer annually worldwide. Although 
the etiology of breast cancer is unknown, numerous risk factors may affect the development of this disease, including genetic, hormonal, environmental, sociobiological, and physiological factors [1].

Breast cancer accounted for $9.8 \%$ of all cancer cases in Korea in 2014 and was the second-most frequently occurring cancer among South Korean females, next to thyroid cancer [2]. Breast cancer in South Koreans appears most frequently in women in their late 40s, followed in order of precedence by those in their $50 \mathrm{~s}$ and $30 \mathrm{~s}$, even though the highest rate is moving gradually toward those in their 50s. The number of breast cancer patients registered between 2000 and 2014 was 79,022 [3].

Interest in breast cancer is one of the important attitudes for women's health management. The five-year survival rate of breast cancer is close to $100 \%$ for stage 0 cancer but less than $20 \%$ for stage IV cancer. Therefore, early detection when there are no symptoms is the best way to improve the survival rate of breast cancer [3]. Breast cancer can be diagnosed definitively with breast selfcheckups, mammography, tomosynthesis, or ultrasonic detection. In South Korea, adults over 40 years of age are recommended to undergo a health checkup every onetwo years, and women, in particular, are strongly advised to undergo breast cancer screening. Therefore, breast cancer is found during the health-screening process in some cases [4].

Breast cancer treatment methods include topical treatments, such as surgery and radiation therapy; systemic therapies, such as chemotherapy, immuno-histochemistry, and target therapy; and multidisciplinary combination therapies that implement at least two of the preceding therapies [5]. Some post-treatment complications are fatigue, weakness, loss of muscle extensibility, limited shoulder range of motion, upper-body pain, pulmonary complications, neuropathy, body composition, and breast cancer-related lymphoedema. Owing to these sequelae, breast cancer patients have limitations in their daily living activities, such as moving objects and closing and opening zippers on clothes. In addition, they complain of psychological problems, such as being forced to give up hobbies, a decline in energy, and feeling as if they have become disabled [6]. Therefore, the symptoms and signs occurring in the treatment process after breast cancer surgery should be prevented and managed. Physical therapy intervention is used in many countries, and the effects have been reported in many studies $[7,8]$. Weight training appears to be safe and beneficial in improving limb strength and physical components of quality of life in women with or at risk of lymphoedema [7]. Early physiotherapy could be an effective intervention in preventing secondary lymphoedema in women for at least one year after surgery for breast cancer involving dissection of the axillary lymph nodes [8]. In South Korea, however, physical therapy interventions are not included in the prevention and management aspects, and there is low public awareness of physical therapy interventions [4].

Therefore, path analysis was used to examine the effect of attitudes toward and interest in health checkups and breast cancer on the perception of and attitudes toward the use of physical therapy after breast cancer surgery. Approaches to enhance the perception of the necessity of physical therapy interventions in breast cancer recovery in South Korea are assessed.

\section{Methods}

\section{Study Design}

This was a cross-sectional study investigating the effects of attitudes toward health checkups and breast cancer on the perception of using physical therapy with South Korean women aged 20 years or older with no history of breast cancer.

\section{Study Subjects and Data Collection Methods}

The data were collected according to the random convenient sampling method for nonprobability sampling 
Table 1. Items of the Major Variables

\begin{tabular}{|c|c|c|c|}
\hline Variable & Items & Variable & Cronbach's $\alpha$ \\
\hline Demographic characteristics & 4 & $\begin{array}{l}\text { Age, education, marital status, } \\
\text { private health insurance }\end{array}$ & - \\
\hline Regular health checkup & 4 & $\begin{array}{l}\text { If I feel well, it is not necessary. } \\
\text { If I follow a healthy lifestyle, I do not feel it is necessary. I have my health } \\
\text { checkup only when I have a health problem. } \\
\text { If I feel healthy, I do not need to see the doctor. }\end{array}$ & .722 \\
\hline Attitude toward BC & 4 & $\begin{array}{l}\text { Breast cancer is like a death sentence. } \\
\text { Breast cancer cannot be cured. } \\
\text { There is very little a woman can do to reduce. } \\
\text { There is nothing she can do to change. }\end{array}$ & .840 \\
\hline Interest in $\mathrm{BC}$ & 1 & Degree of concern about $\mathrm{BC}$ & - \\
\hline Attitude toward PT ABSC & 4 & $\begin{array}{l}\text { PT with ABSC, the necessity of PT ABSC, intent to use PT ABSC, using } \\
\text { PT to return to health }\end{array}$ & .773 \\
\hline
\end{tabular}

BC: Breast cancer, PT: physical therapy, ABSC: After breast cancer surgery

from those using cultural centers, those employed in the workplace, or those who visited hospitals because of diseases unrelated to breast cancer in cases where they agreed to the survey after the study's intent was explained. After the subjects agreed to the survey, they were given a structured questionnaire. Two hundred and thirty-six copies of the questionnaire were collected, and 230 copies of the collected questionnaires were used for the final analysis. Six returned questionnaires that showed consistent median values or had many unanswered items were excluded. The number of subjects required for this study was analyzed using the $\mathrm{G}^{*}$ Power program [9]. The sample size of 134 was appropriate based on an $80 \%$ statistical power bilateral test, a significance level of .01 , and an effect size of .15 .

The participating subjects were provided with a sufficient explanation of the intent and purpose of the study. They were informed that they could withdraw at any time if they did not want to answer the questions and that the collected data would be processed anonymously. When the subjects agreed to participate voluntarily in the study, their written agreements to participate were received, and the questionnaire survey was conducted. The Bioethics Committee of a public institution designated by the Ministry of Health and Welfare of Korea for Research Ethics approved this study (PO1-2016-21-001).

\section{Composition and Reliability of the Study Tool}

The measurement tool used in this study was composed of 17 items in five fields: five items for the demographic characteristics (age, education, marital status, and whether the respondent had private health insurance), four items related to health checkups, four items involving viewpoints on breast cancer, one item related to interest in breast cancer, and four items related to physical therapy after surgery. The questionnaire consisted of 1 point (strongly positive) to 5 points (strongly negative) on a 5-point scale. Table 1 lists the reliability of these questionnaire items.

\section{Analysis Methods}

The collected data were analyzed using the SPSS 21.0 program and the AMOS 21.0 program according to the study purposes, as listed below. The statistical significance level was set to $\mathrm{p}<.05$. 
Table 2. Demographic Characteristics of the Respondents

$(n=230)$

\begin{tabular}{|c|c|c|c|}
\hline & Variable & Frequency & Percent \\
\hline \multirow{5}{*}{ Age groups } & $20-29$ & 42 & 24.3 \\
\hline & $30-39$ & 80 & 34.8 \\
\hline & $40-49$ & 55 & 23.9 \\
\hline & $50-59$ & 19 & 8.3 \\
\hline & $60-69$ & 20 & 8.7 \\
\hline \multirow{3}{*}{ Education } & Never attended, Primary school & 14 & 6.1 \\
\hline & Middle/High school & 81 & 35.2 \\
\hline & College, University or above & 135 & 58.7 \\
\hline \multirow{3}{*}{ Martial status } & Single & 29 & 12.6 \\
\hline & Married & 186 & 80.9 \\
\hline & Divorced/Widowed & 15 & 6.5 \\
\hline \multicolumn{2}{|r|}{ Total } & 230 & 100.0 \\
\hline
\end{tabular}

1) Descriptive statistics were used to assess the general characteristics of the subjects, and the reliability of each research instrument was analyzed using the Cronbach's a values.

2) Cross-analysis was performed on a private health insurance contract with the degree of interest in breast cancer.

3) The subjects' degree of interest in breast cancer and level of physical therapy were analyzed using the means and standard deviations.

4) Path analyses were performed for the relationships among the attitude toward health checkup, viewpoint on breast cancer, degree of interest in breast cancer, and viewpoint on using physical therapy after breast cancer surgery.

\section{Results}

\section{General Characteristics of Survey Subjects}

As shown in Table 2, 24.3\%, 34.8\%, 23.9\%, 8.3\%, and $8.7 \%$ of the subjects were aged 20-29 years, 30-39 years, 40-49 years, 50-59 years, and above 60 years, respectively, indicating that most of the participating subjects were at ages with considerable interest in breast cancer. Regarding the levels of education, $6.1 \%, 35.2 \%$, and $58.7 \%$ graduated from no school or elementary school, middle or high school, and junior college or had a higher education, respectively. Regarding marital status, $80.9 \%, 12.6 \%$, and $6.5 \%$ of the subjects were married, unmarried, and divorced or widowed, respectively (Table 2).

\section{Level of Interest in Breast Cancer and} Awareness of Physical Therapy according to Private Insurance Contract

When asked about a private health insurance contract, $83.5 \%$ answered that they had private insurance, and $16.5 \%$ had no private insurance (Table 3). The association between whether or not they had private health insurance and the degree of interest in breast cancer was statistically significant $(\mathrm{x} 2=13.020, \mathrm{p}<.05)$. In the case of private health insurance, 'very much' and 'a lot' showed high interest in breast cancer $(54.8 \%)$, and only $6 \%$ of those who did not purchase private health insurance reported 'very much' and 'a lot' showed interest in breast cancer. Those who signed up for private health insurance showed higher interest in breast cancer (Table 3). 
Table 3. Private Health Insurance Contract and Degree of Interest in Breast Cancer

\begin{tabular}{|c|c|c|c|c|c|c|c|c|c|}
\hline & & \multicolumn{5}{|c|}{ Degree of interest in breast cancer } & \multirow{2}{*}{ Total } & \multirow{2}{*}{$x^{2}$} & \multirow{2}{*}{$\mathrm{p}$} \\
\hline & & very much & a lot & average & little & very little & & & \\
\hline \multirow{2}{*}{$\begin{array}{l}\text { Have a private } \\
\text { health insurance }\end{array}$} & Yes & $\begin{array}{c}22 \\
(9.6)\end{array}$ & $\begin{array}{c}104 \\
(45.2)\end{array}$ & $\begin{array}{c}46 \\
(20.0)\end{array}$ & $\begin{array}{c}19 \\
(8.3)\end{array}$ & $\begin{array}{c}1 \\
(.4)\end{array}$ & $\begin{array}{c}192 \\
(83.5)\end{array}$ & \multirow{3}{*}{13.020} & \multirow{3}{*}{.011} \\
\hline & No & $\begin{array}{c}4 \\
(1.7)\end{array}$ & $\begin{array}{c}10 \\
(4.3)\end{array}$ & $\begin{array}{c}15 \\
(6.5)\end{array}$ & $\begin{array}{c}9 \\
(3.9)\end{array}$ & $\begin{array}{c}0 \\
(.0)\end{array}$ & $\begin{array}{c}38 \\
(16.5)\end{array}$ & & \\
\hline Total & & $\begin{array}{c}26 \\
(11.3)\end{array}$ & $\begin{array}{c}114 \\
(49.6)\end{array}$ & $\begin{array}{c}61 \\
(26.5)\end{array}$ & $\begin{array}{c}28 \\
(12.2)\end{array}$ & $\begin{array}{c}1 \\
(.4)\end{array}$ & $\begin{array}{c}230 \\
(100.0)\end{array}$ & & \\
\hline
\end{tabular}

Table 4. Degree of Interest in Breast Cancer and Levels of the use of ABSC

\begin{tabular}{cccccc}
\hline Item & $\begin{array}{c}\text { Degree of interest } \\
\text { in breast cancer } \S\end{array}$ & $\begin{array}{c}\text { Use of } \\
\text { physical therapy }\end{array}$ & $\begin{array}{c}\text { Physical therapy is } \\
\text { necessary }\end{array}$ & Intention to use & $\begin{array}{c}\text { Helpful for } \\
\text { recovery }\end{array}$ \\
\hline Score & $3.59 \pm .86$ & $2.74 \pm 1.01$ & $3.51 \pm .85$ & $3.88 \pm .85$ & $3.81 \pm .82$ \\
\hline
\end{tabular}

$\S$ Mean \pm SD, ABSC: after breast cancer surgery.

Table 5. Research Model Fit

\begin{tabular}{cccccc}
\hline GFI & RMR & RFI & IFI & NFI & AGF1 \\
\hline 1.000 & .000 & .913 & .981 & .971 & .959 \\
\hline
\end{tabular}

3. Interest in Breast Cancer and Attitudes Toward Physical Therapy

The degree of interest in breast cancer among the study participants was $3.59 \pm .86$ points, which was between moderate and high. For the question on whether the respondent knew that physical therapy could be used for treatment after breast cancer surgery, the score was 2.74 \pm 1.01 , which is between "I do not know" and "I do not know well," indicating that the level of the perception was low. For items "Physical therapy is needed" (3.51 \pm .85 points), "I may use physical therapy" (3.88 \pm .85 points), and "Physical therapy is helpful for recovery" (3.81 \pm .82 points), the answers were between moderate and high (Table 5).

Therefore, Korean women showed a slightly higher than moderate level of interest in breast cancer, and they had low awareness of the use of physical therapy in the treatment after breast cancer surgery.

\section{Verification of the Goodness of Fit of the Study} Model

The goodness of fit of the path analysis model for women's attitudes toward health checkups, viewpoint regarding breast cancer, degree of interest in breast cancer, and viewpoint regarding the use of physical therapy after breast cancer surgery in relation to the final path diagram was evaluated as follows.

As shown in Table 6, the following values were derived: GFI $=1.000$ (recommended to be at least .9), RMR = .000, RFI $=.913$, IFI $=.981$, NFI (normed fit index) $=$ .971 (fit and good if larger than .9), and AGFI = .959 (recommended to be at least .9). Because the indices generally satisfy the standards compared to the indicators used as general evaluation standards, the indices can be judged to be suitable for explaining the structural influence relationships among the study concepts. 


\begin{tabular}{cccc}
\hline Variables & \multicolumn{2}{c}{ Total effect (Direct effect, Indirect effect) } \\
\hline Variables & Health checkup & Viewpoint on breast cancer Degree of interest in breast cancer \\
\hline Viewpoint on breast cancer & $.481^{* * *}$ & 000 & 000 \\
& $\left(.481^{* *}, .000\right)$ & $(.000, .000)$ & 000 \\
Degree of interest in breast cancer & $.306^{* * *}$ & -.029 & $(.000, .000)$ \\
Viewpoint on the use of physical therapy & $\left.. .320^{*},-.014\right)$ & $(-.029, .000)$ & $.439^{* * *}$ \\
after breast cancer surgery & $\left(.134, .184^{*}\right)$ & $\left(.096^{* * *},-.013\right)$ & $\left(.439^{* * *}, .000\right)$ \\
\hline
\end{tabular}

${ }^{*} \mathrm{p}<.05,{ }^{* *} \mathrm{p}<.01,{ }^{* * *} \mathrm{p}<.001$

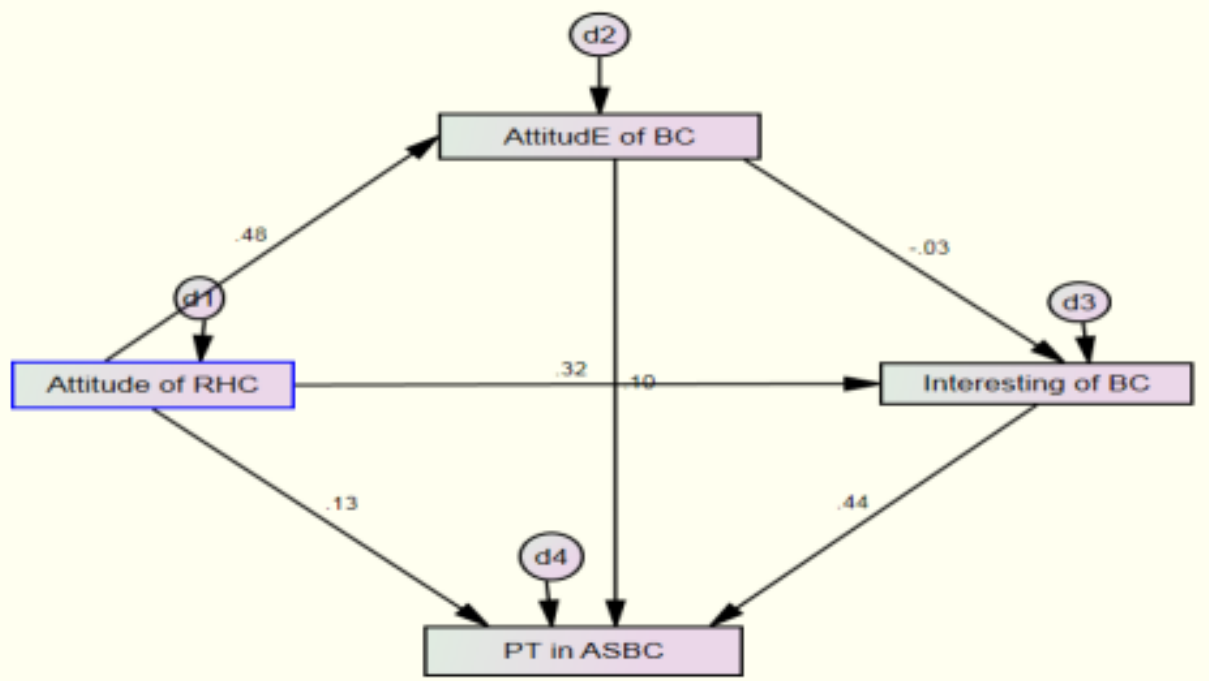

Fig. 1. Path analysis on the application of physical therapy after breast cancer surgery.

5. Path Analysis for the use of Physical Therapy after Breast Cancer Surgery

Table 6 lists the path estimation coefficient values standardized in the study model and the significance levels. Fig. 1 indicates the path model centering on the standardized path coefficients. Among the paths of the model set in this study, the attitudes toward breast cancer were significantly related to the viewpoint on breast cancer $(48.1 \%, \mathrm{p}<.001)$, the degree of interest in breast cancer $(32.0 \%, \mathrm{p}<.001)$, and the viewpoint on the use of physical therapy after breast cancer surgery $(13.4 \%, \mathrm{p}<.05)$. Therefore, the attitudes toward health checkups appear to have explanatory power for the viewpoint on breast cancer, the degree of interest in breast cancer, and the viewpoint on the use of physical therapy after breast cancer surgery. In particular, the explanatory power for the viewpoint on breast cancer was as high as $48.1 \%$.

The degree of interest in breast cancer had a significant effect on the viewpoint regarding the use of physical therapy after breast cancer surgery and explained $43.9 \%$ of the 
cases. The degree of interest in breast cancer had statistically significant effects on the viewpoint regarding the use of physical therapy after breast cancer surgery.

Among the indirect effects, health checkups showed significant effects on the use of physical therapy after breast cancer surgery in the path of the viewpoint regarding breast cancer, thereby showing $18.0 \%$ explanatory power.

\section{Discussion}

Common treatments for breast cancer are surgery, chemotherapy, radiotherapy, hormone therapy, and specific drug therapies, but these interventions commonly induce sequelae that can chronically impair the health status and quality of life (QOL) [10]. Therefore, in the case of breast cancer, management or additional treatment after surgery or in the treatment process is important for the QOL of women.

In path analysis of the model set in this study, the attitudes toward health checkups appear to have explanatory power for the degree of interest in breast cancer and the use of physical therapy after breast cancer surgery. In particular, it had a high explanatory power of $48.1 \%$ for the viewpoint on breast cancer. In other words, the degree of recognition of the need for health checkups has explanatory power of $48.1 \%$ for the attitude toward breast cancer, and the degree of awareness of the necessity of health checkups had explanatory power for the degree of interest in breast cancer and the attitude toward the necessity of physical therapy after breast cancer surgery. Therefore, the attitudes of South Korean women toward health checkups were a major factor in the prevention and treatment of breast cancer. Mullai et al. [11] reported that approximately $100 \%$ of clinical oncologists and radiation oncologists and $80 \%$ of physical therapists and surgeons said physical therapy was necessary for breast cancer patients, thereby reporting high recognition of expert groups. In Korea, a high level of awareness is needed to educate patients on the importance of physical therapy after breast cancer surgery in the expert group.

In foreign countries, physical therapy interventions, such as massaging of scars, stretching exercises for the shoulder muscles, and active and active-assisted shoulder exercises, are generally applied after breast cancer surgery, and the use of physical therapy after breast cancer surgery positively affects the QOL of breast cancer patients $[7,10]$. Physical therapy is used during hospitalization, particularly after surgery, and it teaches how to use the upper limb and how to prevent the risk of lymphedema. Therefore, in Korea, physical therapy should be used after breast cancer surgery to prevent the secondary infection of lymphedema after breast cancer surgery and to improve the QOL of patients. Several exercise methods are suggested for women with breast cancer. Moderate-intensity exercise is recommended. It is best to start a program at low to moderate intensity and progress gradually. Accumulating at least 30 minutes of daily exercise on at least three days each week can lead to benefits. At least 30 minutes of exercise per session, accumulating at least 150 minutes of exercise for more than one week are needed to build up and maintain. Aerobic and supervised resistance training is safe and beneficial. Most sports and specific activities, other than walking and gym-based exercise, have not been well evaluated for safety or efficacy. These exercises will help reduce lymphoedema, fatigue, pain, and nausea and increase circulation [12].

According to Kim [13], those who have breast cancer patients in their surroundings were more likely to undergo self-checkups for breast cancer, which is similar to the results of this study. Furthermore, Paik [13] reported that the proportion of breast cancer caused by genetic factors was only $5-10 \%$ in the West and 2-3\% in South Korea, whereas Park [14] stated that breast cancer occurrence in South Korean women is characterized by a relatively large proportion of genetic predisposition. Kim [13] reported that disability due to breast cancer had the largest effect on 
the performance of self-checkup of breasts, followed by sensitivity, interest in health, age, benefits, and education levels in order of precedence. Anne [15] reported that poverty, family histories of breast cancer, friends with breast cancer, and health affect attitudes toward breast cancer. Paik [3] stated that rich and highly educated groups are more likely to contract breast cancer.

The degree of interest in breast cancer affected the viewpoint on physical therapy after breast cancer surgery and expressed $43.9 .0 \%$ of such cases. In other words, the degree of interest in breast cancer had a significant effect on the viewpoint regarding the use of physical therapy after breast cancer surgery. The limitations of this study were that it did not deal with various factors for breast cancer prevention and that precise standards for private health insurance were not given. In the future, research on introducing and applying various physical therapy interventions for women after breast cancer surgery will be needed.

\section{Conclusion}

This study examined the effects of the attitudes toward and interest in health checkups and breast cancer on the use of physical therapy interventions after breast cancer surgery. The following conclusions were obtained.

South Korean women showed a slightly higher than moderate level of interest in breast cancer, had a low awareness of the use of physical therapy after breast cancer surgery, but had intentions to use physical therapy.

Korean women's attitudes toward regular health checkups are a major factor in the prevention and treatment of breast cancer. A higher level of interest in breast cancer resulted in a higher interest in the use of physical therapy after breast cancer surgery.

Therefore, it is necessary to actively promote the need and effect of the use of physical therapy after breast cancer surgery. In addition, breast cancer checkups are needed when performing regular health checkups, and physical therapy and breast cancer prevention should be promoted using this process.

\section{References}

[1] WHO Regional Office for the Eastern Mediterranean. Guidelines for management of breast cancer. 2006.

[2] http://kosis.kr/statisticsList/statisticsList_01List.jsp? vwcd=MT ZTITLE\&parentId=D\#SubCont.

[3] Paik MS. Current status of breast cancer in Korea. Ewha Med J. 2014;37(2):69-74.

[4] Kim YM, Rho HL. Awareness of physical therapy rehabilitation program after breast cancer surgery in healthy Korean women. J Korean Soc Phys Med. 2018;13(1):39-47.

[5] Rutqvist LE, Rose C, Cavallin-ståhl E. A systematic overview of radiation therapy effects in breast cancer. Acta Oncol. 2003;42(5):532-45.

[6] Karin J. Is physiotherapy useful to the breast cancer patient?. Acta Oncologica. 2005;44:423-4.

[7] Paramanandam VS, Roberts D. Weight training is not harmful for women with breast cancer-related lymphoedema: a systematic review. J Physiother. 2014; 60(3):136-43.

[8] Maria TL, Maria JYS, Alvaro ZG, et al. Effectiveness of early physiotherapy to prevent lymphoedema after surgery for breast cancer. BMJ. 2010;340:b5396.

[9] Cohen JA. Power primer, Psychological Bulletin. 1992;112(1):155-9.

[10] Bobby C, Catherine AG, Kirstin L, et al. Progressive resistance training in breast cancer: a systematic review of clinical trials. Breast Cancer Res Treat. 2008;109(1):926.

[11] Mullai, Dhinakaran, Chanchal G, et al. Awareness of physical therapy rehabilitation for breast cancer related lymphedema among medical oncology team. Int $\mathrm{J}$ Physiother Res. 2013;1(4):161-5. 
[12] Exercise is Medicine Australia. www.exerciseismedicine. org.au. 2014.

[13] Kim MK. Study on breast cancer self-checkup compliance in the context of health belief model. Master's Degree. Ehwa woman University. 1990.

[14] Park BY. Development of sporadic and hereditary breast cancer risk assessment model in Korean women. Doctor's
Degree. Seoul University. 2012.

[15] Anne K. Physiotherapy for the functioning of breast cancer patents : studies of the effectiveness of physiotherapy methods and exercise, of the content and timing of postoperative education and of the experienced functioning and disability. Finland. Uiversity of Jyvaskyla. 2005. 